\title{
MEASURING THE INFLUENCE OF CULTURAL DIMENSION ON CONSUMER BEHAVIOR TOWARDS ONLINE AUTOMOBILE PURCHASE IN PAKISTAN
}

\author{
Muhammad YahyaVana \\ (Primary Author), PhD Student, SZABIST, Karachi \\ vana123@gmail.com \\ Faryal Salman \\ (Co-Author), Assistant Professor, DHA Suffa, Karachi \\ Faryal.salman@dsu.edu.pk
}

\begin{abstract}
Purpose - The main objective of this research was to examine the influence of Hofstede's Cultural Dimension i.e. Power Distance, Masculinity Uncertainty Avoidance, Individualism and Pragmatism on the consumer behavior for the online automobile pre-purchase in Pakistan, an area which was selected primarily due to its recent boom both in the online and traditional channels. Online pre-purchase was studied through its underlying stages which were identified as Perceptions, Need Recognition and Information Search.

Design/methodology/approach - A mixed method approach comprising both Qualitative and Quantitative techniques was adapted in order to execute this research. Initially a focus group comprising four to fiveexecutive students of SZABIST was conducted to investigate into the domain of the research, which followed the administration of a comprehensive questionnaire to four hundred students from different universities in Karachi. The scales for Cultural Dimensions were re used from previous international studies whereas scales for prepurchase stages were developed and verified via a pilot data from the first fifty participants.

Findings - The results indicated that Power Distance (PDI) and Uncertainty Avoidance (UAI) has a significant influence on both Perceptions and Need Recognition for the Online Automobile Purchases in Pakistan suggesting that Pakistani consumers seek lack of special incentives and foresee a considerable risk during these twin pre-purchase stage of Online Automobile Purchase. However, for the stage Information Search of Online Automobiles pre-purchase, besides PDI and UAI the rest of the cultural dimensions i.e. Individualism (IND) and Pragmatism (PRA) which suggests that consumers prefer to gather information from family, peers and coworkers, whereas they are motivated to seek information via most appropriate means often compromising long old traditions or rituals. Tech Saviness also seemed to have a considerable influence in all underlying stages of the pre-purchase, suggesting only those consumers are adaptable to Online Automobiles pre-purchase which are ready to adapt new technology.

Practical implications - the findings of the study provides useful managerial implications for online marketers of high involvement goods in general, and in specific to the automobiles segment. It suggests them to make provisions within their services for consumers which are high on Power Distance, Uncertainty Avoidance, Pragmatism and Individualism in order to ensure better adaptability of their services to their consumers, so as to assure their better satisfaction and thus the success of your business.
\end{abstract}

Keywords:Cultural Dimensions, Online, Shopping, Consumer Behavior, Automobiles, Purchase, Pakistan.

Jel Classification: M31, M15

*The material presented by the author does not necessarily portray the view point of the editors and the management of the Institute of Business \& Technology - IBT

1. Muhammad YahyaVana

:vana123@gmail.com

2. Faryal Salman

:Faryal.salman@dsu.edu.pk

CIBT-JBS is published by the Institute of Business \& Technology - IBT

Main Ibrahim Hydri Road, Korangi Creek, Karachi-75190, Pakistan. 


\section{INTRODUCTION}

Consumer behavior has become an extremely vital field of study for marketers of the $21^{\text {st }}$ century, as the knowledge of how selection, consumption and disposing of products by consumers for different category products and services have gained considerable importance for the success of organizations (Kuester\& Sabine, 2012). Psychological, Sociological, Anthropological, Marketing, Economics, these are some of the academic disciplines from which knowledge is combined in order to make consumer behavioral studies more effective to understand the decision-making processes of buyers, at both individual as well as in the form of groups.

However, it is due to note that the prediction of consumer behavior is not an easy task (Armstrong, 1991), as multiple factors may be playing their role simultaneously which maybe in the form of internal and external influences. Internal influences maybe in the form of demographics, psychographics, attitudes, beliefs, feelings and etc. whereas external influences maybe in the form of society, family, social status, previous experiences, culture and etc. Culture has a predominant role in the consumer behavior, whereas it has also been the center of many researches around the world in order to understand the integration of culture with different aspects of consumer behavior. Without a doubt, culture establishes the traditions, norms upon which the whole framework of the consumer behavioral studies rest upon (Mooij, 2010).

However, culture itself is not an easy aspect to understand, but The National Culture Theory (Hofstede Model, 2010) has programmed culture in such a way that it becomes easier to differentiate one group of people from another by defining 5 distinct dimensions namely as follows:
- $\quad$ Power-distance
- $\quad$ Collectivism vs. individualism
- $\quad$ Femininity vs. masculinity
- Uncertainty avoidance
- $\quad$ Long- vs. short-term orientation

Much of these above five dimensions are used in previous researches in order to study the impact on consumer behavior with specific to their preferences, attitudes and perceptions at different parts of the world. For instances, differences in consumer behavior from Australia and Asia were explained with the help of differences in the culture as explained by these cultural dimensions. (Nayeem, 2012). Recently, these cultural dimensions have also been a focus of a lot of researches for consumer behavior for Online Purchasing goods via an ECommerce medium.

With the advent of information technologies, the consumers have been embarked with a contemporary channel for purchasing of goods via websites and online portals, which as opposed to traditional channels have gained quite a lot of popularity and have impacted behavior of consumers in terms of their preferences to shop for goods (Maddox \& Gong, 2012). Studies have taken into account, online apparel purchasing as an example to compare two cultures for their preferences and perceptions for such online modes of purchasing with reference to Cultural Dimensions. (Brosdahl\&AlMousa, 2012). Nevertheless, other studies were also focused on high involvement goods such as automobiles for studying the impact of cultural dimensions on the consumer behavior. 
Automobiles within the category of high involvement goods, has been a focus of all such cultural dimensions and consumer behavior studies has been a focus particularly worldwide, because they present opportunities to study from different aspects and possibilities such as consumer brand loyalty to quality, technological innovation as well as an array of other factors to judge the taste and preferences of consumers along cultures worldwide. Talking exclusively about Pakistan, this sector also poses immense potential and future growth, especially in the online world with the introduction of automobile selling \& purchasing portals such as Pakwheels, OLX, carmudi, and many other similar websites. However, it is due to note that all such websites, assists the consumers during the pre-purchase stages such as assisting them with the required information about the potential buyers and sellers of automobiles online via portals. Blogs, newsletters and social media content assists in the development of need of the consumers as well.

Cultural orientations significantly influence consumer behavior and academicians are trying to investigate as to how these dimensions influence purchase of high involvement product, in this case automobile where considerable risk is involved. Thus the main research question of this study arises as to what is the influence of cultural dimensions in online purchase of automobiles and how significant this relationship is. The study has restricted itself to the prepurchase stage of buying behavior considering the fact that Pakistani consumers are merely interested in using online car buying and selling mechanism in the formulation of perception about the sellers, need recognition and information search. As identified by Hofstede, Pakistani society is highly Collectivistic, high on Uncertainty Avoidance, Masculine and more prone to exhibiting Power Distance. Henceforth, the influences of all these dimensions are studied in context of online automobile purchase. Keeping in view the global popularity for using online mechanism to purchase consumer durables and high involvement product the findings of this study has a lot of practical and academic significance. The empirical findings will help local and international marketers of automobiles to understand the relevance of cultural dimensions and design marketing strategies and sales pitch accordingly and make use of the contemporary e-tailing format which is a new sales channel. The findings of this study will also contribute in the body of academic knowledge as this study offers a holistic framework that incorporates all aspects of cultural dimensions in pre-purchase stage of high involvement product through a new and evolving sales channel specifically in context of developing countries.

\section{LITERATURE REVIEW}

Conflict begins at the very definition of culture, the studies of which roots back to the $17^{\text {th }}$ century. Early scholar included Edward Taylor (1962) who used culture to refer members of the society on a global scale.Hoebel (1965) describes culture as an integrated system of learned behavior patterns which are characteristic of the members of a society and which are not a result of biological inheritance. Major contributions came from scholars who included Hofstede (1991), Oksaar (1988) and Wierzbicka (1992). The idea of a Universal Human Concepts and the language was introduced by Wierzbicka. However, after a quick view of the work done by the scholars, one is easily convinced that there is a lot of differentiation between each viewpoint.

However, the idea of cultural dimensions begins with three prominent scholars namely Hofstede, Hall and Gesteland. Almost all theories of cultural dimensions have some drawbacks and setbacks, and therefore they must be used and applied very carefully. Even Hofstede had received severe criticisms from renowned experts and senior scholars from time to time; however, his work remained to be and will continue to be used in different 
management and scientific school of studies. His concepts laid the basis and therefore made connections with various prevailing theories

"Culture is the collective programming of the mind distinguishing the members of one group or category of people from others." (Hofstede, 2010) Comprehensive studies were also conducted to identify a number of groups which are commonly referred as 'Hofstede dimensions of National Culture. This dimensional model of National Culture has been used extensively in global marketing, advertising and the underlying theories of consumer behavior, which defines the selection of this model for this paper (Hofstede \& Mooij, 2010). The model has been used to explain differences of the concepts of self, personality and identity, which in turn explain variations in branding strategy and communications. Another area is information processing, including differences in perception and categorization that influence interpersonal and mass communication, and the working of advertising. Thus a quick outlay of these dimensions is as under:

\section{Power Distance (PDI)}

This dimension expresses the degree to which the less powerful members of a society accept and expect that power is distributed unequally. The fundamental issue here is how a society handles inequalities among people. People in societies exhibiting a large degree of power distance accept a hierarchical order in which everybody has a place and which needs no further justification. In societies with low power distance, people strive to equalize the distribution of power and demand justification for inequalities of power.

\section{Individualism versus Collectivism (IDV)}

The high side of this dimension, called individualism, can be defined as a preference for a loosely-knit social framework in which individuals are expected to take care of only themselves and their immediate families. Its opposite, collectivism, represents a preference for a tightly-knit framework in society in which individuals can expect their relatives or members of a particular in-group to look after them in exchange for unquestioning loyalty. A society's position on this dimension is reflected in whether people's self-image is defined in terms of "I" or "we."

\section{Masculinity versus Femininity (MAS)}

The masculinity side of this dimension represents a preference in society for achievement, heroism, assertiveness and material rewards for success. Society at large is more competitive. Its opposite, femininity, stands for a preference for cooperation, modesty, caring for the weak and quality of life. Society at large is more consensus-oriented. In the business context Masculinity versus Feminity is sometimes also related to as "tough versus gender" cultures.

\section{Uncertainty Avoidance (UAI)}

The uncertainty avoidance dimension expresses the degree to which the members of a society feel uncomfortable with uncertainty and ambiguity. The fundamental issue here is how a society deals with the fact that the future can never be known: should we try to control the future or just let it happen? Countries exhibiting strong UAI maintain rigid codes of belief and behavior and are intolerant of unorthodox behavior and ideas. Weak UAI societies maintain a more relaxed attitude in which practice counts more than principles. 


\section{Long-Term Orientation (LTO) or Pragmatism (PRA)}

Long term orientation dimension represents the degree to which, societies are linked to their past while dealing with the challenges of the present and the future. Societies prioritize these two existential goals differently. (Bond, 1991)

\section{Pakistan}

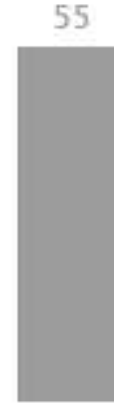

Power Distance

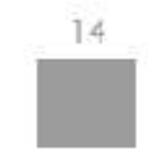

Individualism Masculinity

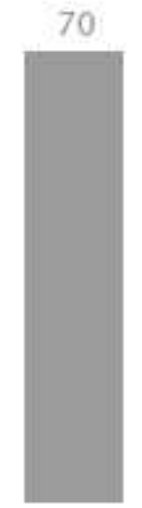

Uncertainty Avoidance

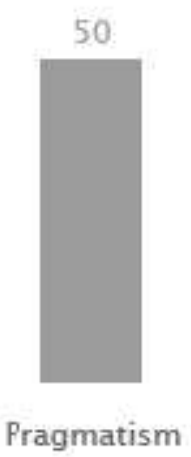

Scores of Pakistan for Hofstede National Culture

\section{Marketing Implications of Hofstede's Cultural Dimensions}

Several scholars have focused National Culture Theory (Hofstede 2010) as a center for their researches worldwide to establish consumer behavior linkages with culture. The dimension of Uncertainty Avoidance (UAI) has been extensively to assess the perceived risk by the consumers in online shopping and has proven to have sizable effect on the behavior of consumers in the online information and sales channels (Kailani and Kumar 2012). Similarly, Power Distance (PDI) has been assessed with its association with the consumer behavior with shopping of many luxurious goods and services and it has been established to be a significant predictor of consumer behavior for luxurious goods and services (Jung and Kau2004). Whereas, the cultural dimension Pragmatism (PRA), has also been a focus of consumer behavior studies, in that scholars have established that consumers in high involvement goods are willing to forego long term traditions and willing to accept current challenges (Mulaomerovic and Trappe 2013).

\section{Online Purchasing}

Online Purchasing has been the center of all such studies, as it has gained quite popularity recently. According to UCLA (2001), E-commerce has become one of the most important activity on the internet, whereas Nielsen (2014) established that Asian countries have shown unprecedented growth in the online shopping world particularly in the shopping of computer hardware and some other travel services, Nevertheless, it still present a huge potential in terms of dollar revenues from online \& e-retailing transactions, if certain bottlenecks such as fear and insecurity of payments is removed. Nielsen (2014) also claimed that with more penetration of more technological gadgets, such as in the form of smart phones, laptops and other computing technologies, the consumers in general will becoming more tech savvy and hence this overall effect will act in the promotion as well as adaptation of online purchasing habits of the Asian consumers.

Different factors has been observed to study these online purchases, for example Case, Burns and Dick (2001) suggests demographics of the users to be powerful predictors of Internet 
Purchases, whereas Ho and Wu (1999) describes the quality factors which appeal to the online consumers. While all such researches were done internationally, none of such attempts have been made in Pakistan in order to study understand the orientation of the consumers and their preferences in the online world which has recently witnessed an upheaval growth in ecommerce in the form of online stores for consumer goods such as Daraz.pk, Kaymu.pk, Homeshopping.pk, etc. as well as online portal for automobiles which are providing listings for cars and promoting consumer buying \& selling of automobiles in Pakistan. This trend is expected to show a continuous upward trend because there is a booming generation in Pakistan, which is tech savvy i.e. more adapted towards online world through their gadgets in the shape of high end smart phones, tablets, laptops and other similar devices.

\section{Automobiles Sector in Pakistan}

The automobiles sector in general has witnessed a great boom recently due to the constant innovation of the local manufacturers as well as bombardment of used imported automobiles from Japan. In this overall growth patterns, these online automobiles listings provide act as potential information stores for the consumers in Pakistan, which not only help potential buyers develop their need but also act as potential information seeking tools to assist them during their pre-purchase stages.

Hence, based on the literature the proposed model of relationship of is as follows:
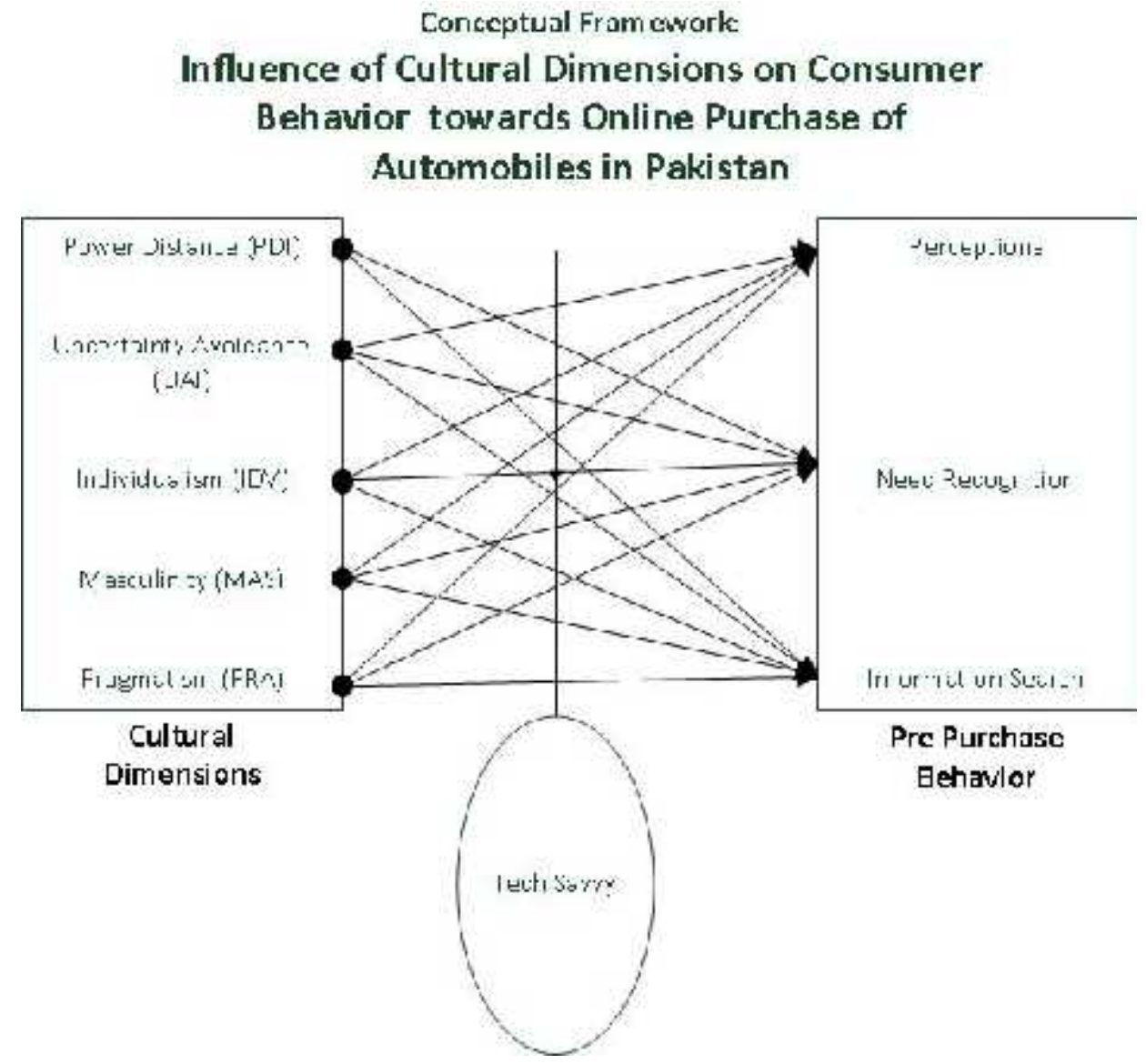

The figure illustrates the conceptual framework. Cultural Dimensions are bifurcated into variables namely Power Distance (PDI), Uncertainty Avoidance (UAI), Individualism (IDV), Masculinity (MAS) and Pragmatism (PRA) the effects of which collectively are being studied 
on each of the aspects of Pre-Purchase Behavior of the consumers which is defined by the variables Perceptions, Need Recognition and Information Search.

It is due to note that a moderating variable in the form of Tech Savviness is also incorporated in this paper, because literature suggested that consumers which are more adaptable to technologies are the one who engages more in the online pre-purchasing stages. Therefore, in order to see the effect on this variable, Tech Saviness has been added as a moderating variable.

\section{Hypothesis:}

H1: Cultural Dimensions is a significant predictor of Consumer Perceptions of Online purchasing of Automobiles in Pakistan

H2: Cultural Dimensions is a significant predictor of Consumer Need Recognition of Online purchasing of Automobiles in Pakistan

H3: Cultural Dimensions is a significant predictor of Consumer Information Search of Online purchasing of Automobiles in Pakistan

\section{RESEARCH METHODOLOGY}

This was an exploratory as well as explanatory research in nature. The first part of the research dealt with the exploration of the consumer behavior in our pre-purchase online purchasing research domain whilst the second part dealt with deducing the reasons and attaching explanations to the observed behavior from the first part. This was also the reasons that a mix-method was selected as a choice to conduct this research which was in the form of both qualitative and quantitative study. Qualitative method was incorporated within the research by a focus group of 4-5 respondents from the target population in order to preliminary investigate the domain of the research, whereas quantitative method which was executed through a survey research questionnaire instrument to various university students in Pakistan.

Thus, after data collection from the participants a causal relationship was established amongst each of the five Hofstede's cultural dimension with each of the three aspects of the consumer behavior i.e. perceptions, information search and need recognition.

The population of this study were designed from two different clusters, the first of which were the University students, whilst the second cluster belonged to the Working Professionals residing in the urban metro of Karachi. This set of population is shortlisted from the other population, because these people have the cognitive skills to understand and fill the required questionnaires as opposed to other classes of citizens. There were many reasons for the inclusion of these two different clusters. Firstly, the working professionals exhibit the sound financial standing for purchasing of automobiles, and therefore they are unarguably direct purchasers of the automobiles in Pakistan, whereas University Students as a prospective target population of our research. One of the most important reasons behind involves that they are potential future consumers of the Pakistani market in the domain of goods that the research is being made. They are also potentially the most recipients of the online promotions, as they spend majority time online during their study work.

The total population for this research was estimated to be $\mathbf{8 8 , 0 0 0}$. Hence a sample size of 400 respondents is estimated based on $10 \%$ margin of error and $99 \%$ confidence interval of the 
population. Probabilistic cluster sampling was employed for picking up this sample of 400 respondents from each of the underlying groups of the population.

A comprehensive Survey Questionnaires was designed and administered, which fairly covered all aspects to ascertain the level of consumer preferences, need recognition and information search for online automobile purchase. The scales of this instrument particularly pertaining to the consumer behavior variables i.e. Perceptions, Need Recognition and Information was self-developed, which were designed and operationalized in such a way to incorporate cultural dimensions in their constructs in order to ensure substantial explanation power in the further stages of the analysis, whereas scales of the Hofstede's Cultural Dimensions were taken from previous international studies.

The reliability of the research instrument was checked by Cronbach's Alpha Coefficient. Whereas, the validity of the instrument was ensured by the face validity from the domain experts in the field of Pakistan.

\section{DATA ANALYSIS}

Reliability of the research instruments was checked both at an overall level, as well as at each variable level. As observed, the Cronbach alpha scores are all above 0.5 level, which considering the sample size of 400 , are satisfactory to proceed for further analysis. There were 64 total items which were divided into different variables. Approximately 13 for each perceptions, need recognition and information search whereas 4 items for each of the Cultural Dimensions.

From the correlation matrix(Table 1b), significant correlations of Cultural Dimensions were observed amongst dependent and independent variables but also within cultural dimensions and also within perceptions, need recognition and information search, indicating successful linkages of the variables within one another. As observed Power Distance (PDI), Uncertainty Avoidance (UAI) and Pragmatism (PRA) shows significant correlations with almost all aspects of consumer behavior i.e. Perceptions, Need Recognition and Information Search. However, low correlations scores in the matrix is because of the presence of other factors or reasons which may not be explained by the model of this paper. The Regression results(table 1a) conforms the earlier correlation analysis of the variables and substantiates the existence of influence of cultural dimensions on all variables of pre-purchase consumer behavior i.e. Perceptions, Need Recognition and Information Search. The results for Perceptions as dependent indicate significant prediction by Uncertainty Avoidance and Power Distance, where $\mathrm{t}>3$; whereas, result Need Recognition as dependent indicate significant prediction by Power Distance and Pragmatism, where $t>2.5$; while results for Information Search as dependent indicate significant prediction by Power Distance and Pragmatism, where $\mathrm{t}>$ 3.However, it is due to note that lower values of adjusted R-square i.e. $11.6 \%, 11.3 \%$ and $14.2 \%$ was observed in the 3 regression analysis for Perceptions, Need Recognition, Information Search respectively. These low scores can be due to the presence of multiplicative factors in the domain of this search. Firstly, it could be due to the presence of more variables in the form of moderating variables in the form of consumer demographics such as age, education, income and etc. or maybe due to some more independent variables besides the cultural dimensions such as the characteristics of the services being offered by these online websites. All such variables were not included in the model of this paper and thus could be potential sources for low correlation scores of this regression analysis. 


\section{Discussion and Finding}

Based on the results obtained from the data analysis, the correlations were used to determine the existence of relationships between the cultural dimensions with the prepurchase stages, whereas the results of the regression analysis were used to determine the extent of this influence in the form of coefficients. Finally, the descriptive analysis each of the items within helped in the determination in explaining and reasoning of the obtained results.In the aftermath of the obtained results our all three hypotheses are accepted which asserts that Cultural Dimensions are a significant predictor for the consumer perceptions, consumer need recognition and information seeking in the online automobile pre-purchase in Pakistan.Further, analyzing the above results we have observed that cultural dimension, Uncertainty Avoidance, Power Distance and Pragmatism have the most influence on the consumer behavior for the online purchase of automobiles in Pakistan, hence there reasons were further assessed for the purposes of this research.Uncertainty Avoidance (UAI) plays a key role in online pre-purchase consumer behavior because consumers think that incomplete information is prevailing about automobiles on online websites, and that the level of transparency that they can attain from the contemporary purchasing channel i.e. through the online dealerships, cannot be achieved in the online channel. This result was synonymous with previous researches which established that consumers perceive risk in Online buying (Kailaniand Kumar 2011).Power Distance (PDI) seems to exhibit influence because consumers require to be treated and entertained via dedicated experts such as showroom \& dealerships agents, which are perceived to be the expert in this field. This again conforms results of previous worldwide researches which asserts that consumers demand VIP treatment, loyalty programs and similar treatments (Jung and Kau2004).Whereas, Pragmatism (PRA)seems to be playing its part primarily because automobiles being a high involvement and a durable good, therefore consumers tend and want to forego their old traditions and methods, and are willing to practice effective and more practical methods in order to practice more carefulness and meticulousness in their approach, this again was a result which was expected as similar research by Gong, Maddox, and Stump (2012)established similar results.

\section{Conclusion}

This paper contributed by establishing that Cultural Dimensions and particularly Power Distance, Uncertainty Avoidance and Pragmatism within the cultural dimensions are significant predictors of Online Automobile Pre-purchase consumer behavior in Pakistan. Therefore, several marketing implications can be drawn from this paper for the marketers of online automobile as well as other durable and high involvement goods. Firstly, they should aware that cultural dimensions play a key role in the channel selection for the pre-purchase of goods, and hence they must design their sales and information channels accordingly. Secondly, if their existing channels are designed to cater to the requirements of their consumers which are high on the cultural dimension index of Power Distance, Uncertainty Avoidance and Pragmatism, then they will definitely witness better adaptability of their services for the consumers in Pakistan. Just like any other research, this paper too also acknowledges its limitations, Firstly; it was conducted only in one particular city of Pakistan which was Karachi. Secondly, there could be an array of other moderating variables to this research such as in the form of income, education and other similar demographical variables. Nevertheless, this research provides sufficient ground for further similar researches in this field in order to understand the complete picture on the online world more elaborately. 


\section{Significance of the Study}

This paper presents useful theoretical as well as managerial implications for online marketers of high involving products particularly to the automobiles sector. Theoretically, this paper has presented a strong linkage and has established Hofstede's cultural dimensions as a significant predictor of the online pre purchase behavior of the consumers, which establishes the ground for managerial implications that marketers should consider and take into account their target consumers' orientation along with the cultural dimensions, and thus should amend their online and sales channels accordingly. For instance, if the target consumers are high on the dimension of Power Distance (PDI), sales channels must be designed to cater to their need to treated especially via loyalty programs, VIP treatments, as well as by other means. Similarly, for consumers which are high on the index of Uncertainty Avoidance (UAI), special assurances such as certifications from regulatory bodies maybe required and displayed to eliminate the consumer's fear of being cheated or deceived. Thus, this study educates the marketers to be aware of their consumer's position on the cultural dimension indices in order to be able to ensure their better satisfaction.

\section{Area of Further Research}

Although, this study specifically chose the automobiles, a high involvement good, for which the consumer uses the online sales channel for their pre purchase stages such as Need Recognition and Information Seeking, but recently, there are an array of fashion, electronic and other types shopping goods along with several services such as airline ticketing, hotel booking, vacation planning and several others which has recently sprang up on the online world which can also be made focus as an extension of this research, to see the relationship of Hofstede's cultural dimensions with the pre purchase, during purchase as well as post purchase behavior of the consumers. Thus, researchers may conduct a similar study on fashion goods, electronic items, travel services to assess the status of relationship with the Cultural Dimensions..

\begin{tabular}{|l|l|l|}
\hline Variable & Number of Items (N) & $\begin{array}{l}\text { Cronbach's } \\
\text { Alpha }\end{array}$ \\
\hline Overall Reliability & 64 & 0.859 \\
\hline Perceptions & 13 & 0.668 \\
\hline Need Recognition & 14 & 0.728 \\
\hline Information Search & 13 & 0.631 \\
\hline Power Distance & 4 & 0.582 \\
\hline Individualism & 4 & 0.705 \\
\hline Uncertainty Avoidance & 4 & 0.592 \\
\hline Masculinity & 4 & 0.507 \\
\hline Pragmatism & 4 & 0.518 \\
\hline Tech Saviness & 4 & 0.738 \\
\hline
\end{tabular}


Table 1a: Regression Analysis

\begin{tabular}{|c|c|c|c|c|c|c|}
\hline Criteria Variable & $\boldsymbol{\beta}$ & $\mathbf{t}$ & $\mathbf{R}^{2}$ & $\operatorname{Adj} R^{2}$ & $\mathbf{F}$ & Sig. \\
\hline (Constant) & & 10.588 & .134 & .116 & 7.186 & $.000^{\mathrm{a}}$ \\
\hline Power Distance & .182 & 3.116 & & & & \\
\hline Individualism & .091 & 1.49 & & & & \\
\hline Uncertainty Avoidance & .196 & 3.221 & & & & \\
\hline Masculinity & .037 & .604 & & & & \\
\hline Pragmatism & -.031 & -.494 & & & & \\
\hline Tech Savvy & .082 & 1.29 & & & & \\
\hline \multicolumn{7}{|c|}{ a.Dependent Variable: Perceptions } \\
\hline & \multicolumn{5}{|c|}{ Criteria Variable } & Sig. \\
\hline (Constant) & & 8.326 & .196 & .179 & 11.328 & $.000^{\mathrm{a}}$ \\
\hline Power Distance & .381 & 6.765 & & & & \\
\hline Individualism & -.005 & -0083 & & & & \\
\hline Uncertainty Avoidance & .026 & .446 & & & & \\
\hline Masculinity & .085 & 1.449 & & & & \\
\hline Pragmatism & .153 & 2.559 & & & & \\
\hline Tech Savvy & -.014 & -.223 & & & & \\
\hline \multicolumn{7}{|c|}{ a.Dependent Variable: Need Recognition } \\
\hline \multicolumn{6}{|l|}{ Criteria Variable } & Sig. \\
\hline (Constant) & & 7.871 & .235 & .218 & 14.182 & $.000 \mathrm{a}$ \\
\hline Power Distance & .172 & 3.126 & & & & \\
\hline Individualism & .127 & 2.216 & & & & \\
\hline Uncertainty Avoidance & .104 & 1.824 & & & & \\
\hline Masculinity & .108 & 1.88 & & & & \\
\hline Pragmatism & .197 & 3.377 & & & & \\
\hline Tech Savvy & .127 & 2.128 & & & & \\
\hline
\end{tabular}

Table1b: Pearson Correlation Matrix

\begin{tabular}{llllllllll}
\hline & PER & NR & IS & PDI & IDV & UAI & MAS & PRG & TS \\
\hline PER & 1 & & & & & & & & \\
NR & $.413^{* *}$ & 1 & & & & & & & \\
IS & $.376^{* *}$ & $.444^{* *}$ & 1 & & & & & & \\
PDI & $.249^{* *}$ & $.409^{* *}$ & $.241^{* *}$ & 1 & & & & & \\
IDV & $.179^{* *}$ & .099 & $.276^{* *}$ & $.151^{*}$ & 1 & & & & \\
UAI & $.285^{* *}$ & $.163^{* *}$ & $.259^{* *}$ & $.233^{* *}$ & $.245^{* *}$ & 1 & & & \\
MAS & $.148^{*}$ & $.161^{* *}$ & $.267^{* *}$ & $.155^{* *}$ & $.273^{* *}$ & $.231^{* *}$ & 1 & & \\
PRG & .086 & $.173^{* *}$ & $.316^{* *}$ & -.004 & $.243^{* *}$ & $.250^{* *}$ & $.207^{* *}$ & 1 & \\
TS & $.152^{* *}$ & .071 & $.283^{* *}$ & .009 & $.263^{* *}$ & $.211^{* *}$ & $.321^{* *}$ & $.382^{* *}$ & 1 \\
\hline \multirow{2}{*}{$*$ C Correlation is significant at the 0.01 level (2-tailed). } & & & & & \\
\hline
\end{tabular}




\section{REFERENCES}

Case, T., Burns, O. M., and Dick, G. N. .Drivers of on-line purchasing among U.S. university students.. Proceedings of the $7^{\text {th }}$ Americas Conference on Information Systems, 2001, pp. 873-878.

Gong, W., Maddox, L. M. \& Stump, R. L. (2012). Attitudes toward Online Shopping: A Comparison of Online Consumers in China and the US, International Journal of $\mathrm{E}$ Business Development (IJED), 2(1), 28-35.

Ho, C., and Wu, W.(1999) .Antecedents of consumer satisfaction on the Internet: an empirical study of online shopping,. Proceedings of the 32nd Hawaii International Conference on system sciences.

Kailani, M.A. \& Kumar, R. (2011). "Investigating Uncertainty Avoidance and Perceived Risk for Impacting Internet Buying: A Study in Three National Culture," International Journal of Business and Management, 6(5),76-92.

Kwon, Ah KengKau (2004), "Culture's Influence on Consumer Behaviors: Differences Among Ethnic Groups in a Multiracial Asian Country," Advances in Consumer Research 31,366-372.

Marieke de Mooij (2010): Consumer Behavior and Culture: Consequences for Global Marketing and Advertising,California Thousand Oaks, Sage.

Marieke de Mooij and Hofstede (2010), "The Hofstedemodel:Applications to global branding and advertising strategy and research,'International Journal of Advertising: The Review of Marketing Communications , (29) 1, 85-110.

Mulaomerovic, E. \& Trappe, C.V. (2013). The role of cultural dimensions in the acceptance of retail innovations, Management, paper presented at Knowledge \& Learning International Conference, Zadar Croatia

Nayeem, T. (2012). Cultural Influences on Consumer Behavior, International Journal of Business and Management; 7(21),78-91.

Nielsen (2014, August 26) Southeast Asian Consumers Flock Online To Purchase Products AnD Services retrieved from http://www.nielsen.com/apac/en/insights/news/2014/southeast-asian-consumersflock-online-to-purchase-products-and-services.html 